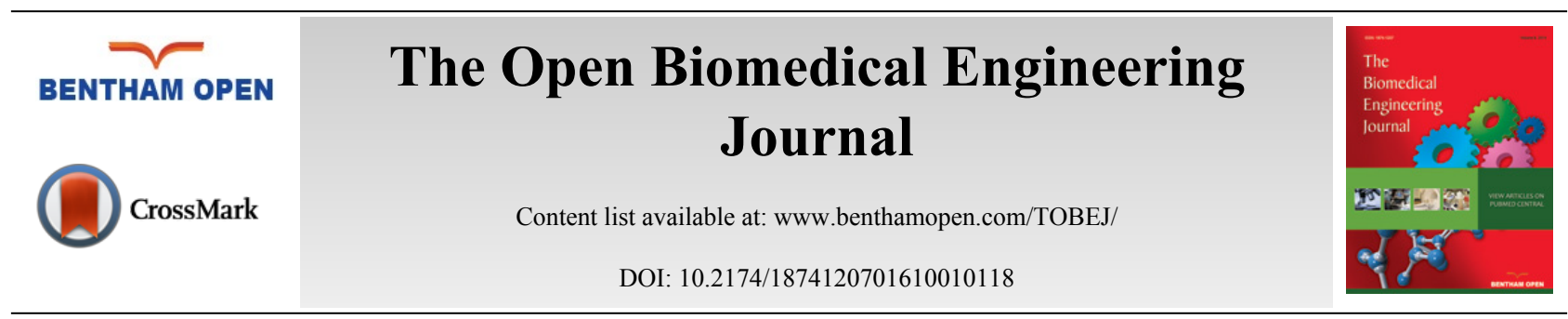

\title{
RETRACTION
}

\section{Retraction Notice: Research and Implementation of Children's Speech Signal Processing System}

Lei Xue ${ }^{*}, 1$, Zhi Zhang ${ }^{1}$, Xiaoyang Zhang ${ }^{1}$ and Yiwen Zhang ${ }^{2}$

${ }^{1}$ School of Communication and Information Engineering, Shanghai University, Shanghai, 200000, P.R. China

${ }^{2}$ Shanghai Children's Medical Center, Shanghai, 200000, P.R. China

\section{RETRACTION}

The Publisher and Editor have retracted this article [1] in accordance with good ethical practices. After a thorough investigations we believe that the peer review process was compromised. The article was published on-line on 31-08-2015.

\section{REFERENCES}

[1] L. Xue, Z. Zhang, X. Zhang, and Y. Zhang, "Research and implementation of children's speech signal processing system", Open Biomed. Eng. J., vol. 9, pp. 188-193, 2015.

(C) Xue et al.; Licensee Bentham Open.

This is an open access article licensed under the terms of the Creative Commons Attribution-Non-Commercial 4.0 International Public License (CC BY-NC 4.0) (https://creativecommons.org/licenses/by-nc/4.0/legalcode), which permits unrestricted, non-commercial use, distribution and reproduction in any medium, provided the work is properly cited.

* Address correspondence to this author at the School of Communication and Information Engineering, Shanghai University, 200000, P.R. China; Email:16301098@163.com 